Article

\title{
Does Death Anxiety Moderate the Adequacy of Retirement Savings? Empirical Evidence from 40-Plus Clients of Spanish Financial Advisory Firms
}

\author{
Pablo Garmendia ${ }^{1}$, Gabriela Topa ${ }^{2, *\left(\mathbb{D} \text {, } \text { Teresa Herrador }^{3} \text { and Montserrat Hernández }\right.}{ }^{3}$ \\ 1 Universidad Nacional de Educación a Distancia UNED, Ph.D. Programme in Psychology and Health, \\ International School of Doctorate, 28040 Madrid, Spain \\ 2 Department of Social and Organizational Psychology, Universidad Nacional de Educación a Distancia \\ UNED, 28040 Madrid, Spain \\ 3 Department of Business Economics and Accounting, Universidad Nacional de Educación a Distancia UNED, \\ 28040 Madrid, Spain \\ * Correspondence: gtopa@psi.uned.es; Tel.: +34-913988911; Fax: +34-913986215
}

Received: 11 April 2019; Accepted: 3 July 2019; Published: 8 July 2019

check for updates

\begin{abstract}
This three-wave study analyses the mediating role of financial behavior in the relationship between financial goals and retirement saving adequacy, and the moderating role of Death anxiety. The participants in the study $(\mathrm{N}=276)$ were 40-plus Spanish clients of financial advisory firms. The results show that the relationship between financial goals and retirement saving adequacy is, in fact, mediated by financial behavior. We also found that death anxiety moderates the financial behavior-retirement saving adequacy relationship. The theoretical and practical implications of the study for design are discussed at the end of the paper.
\end{abstract}

Keywords: death anxiety; financial goals; retirement; financial behavior

\section{Introduction}

The proximity of death can be associated with feelings of fear and anxiety. Old age and other social indicators of life's passing, like retirement, eventually oblige us all to address our own mortality. Unsurprisingly, then, events of this kind can provoke unease, gloom, and feelings of dread and forebode (Cai et al. 2017). Death anxiety (hereafter, DA) is a complex emotional phenomenon, which includes apprehension both for oneself and for loved ones (Templer 1970). A growing body of empirical evidence shows that DA impinges on most spheres of life, and specifically on financial behavior (Osborne 2016).

Retirement is a life-changing event from the personal standpoint because it marks the obligatory end of work and serves as a reminder of aging, failing health and, eventually, death (Osborne 2016). Recent research supports the frequent association of retirement with negative thoughts, troubling emotions, and anxiety about the future in different areas of life (Park et al. 2017). Given the financial implications of the end of paid work, as well as the health implications of money, retirement savings adequacy is a key concern (Huston 2010).

Nowadays, population aging in the developed countries has intensified pressure on public pension systems. As the cost of public pension provision has inexorably risen, so concern over the viability of delivery systems has grown (Dong et al. 2019). Saving for retirement offers individual assurance of well-being in the long term. It now seems clear that society will not be able to guarantee the quality of life in retirement unless people save on their own behalf, leading governments increasingly to adopt active policies designed to involve citizens in achieving retirement savings adequacy (Budowski et al. 2016). 
Financial behavior is, of course, influenced by multifarious factors above and beyond earnings levels. It might be supposed that higher earners would be those who save the most, but the evidence casts some doubt on this assumption (Han et al. 2015). To begin with, research into the precursors of financial behavior has shown that people with clear, specific financial goals achieve enhanced levels of execution in practice (Stawski et al. 2007). Furthermore, those who use the services of financial advisors may be better placed to clarify their goals and specify more precisely the steps they need to take to realize them. Meanwhile, the influence of emotional factors and personal fears on financial behavior is becoming increasingly clear (Topa and Herrador-Alcaide 2016). Research in this area reveals how death anxiety can influence consumer behavior and financial decisions (Nepomuceno and Laroche 2016). In this light, we need to explore retirement savings adequacy and its relationship with financial behavior and financial goals. To be specific, this dataset looks at the moderating role of DA in relation to financial goals and retirement savings adequacy as mediated by financial behavior among a sample of a 40-plus client of Spanish financial advisory firms.

To sum up, based on Huston's (2010) theoretical model, this data set is aimed to provide participant's answers on the predictors, mediators, and moderators of retirement savings adequacy when people are proximal to retirement. Considering that common method bias could affect self-report studies, the temporal separation of predictors and criterion variables was applied as a procedural remedy. Hence, the present study includes three times of data collection: Time 1 (T1) Financial Goals and Death Anxiety; Time 2 (T2) Financial Behavior and Time 3 (T3) Retirement savings adequacy. The findings that could be obtained from this dataset will guide interventions to improve literacy and promote independence, wealth, health, and well-being among people from young adulthood to old age.

\subsection{Retirement Savings Adequacy}

The cost of public pension provision continuously increased in developed countries. Moreover, forecasts indicate that it will continue to grow, reaching $10.1 \%$ of GDP by 2050, at least in the advanced economies. Because of this, governments have increasingly sought to encourage their citizens to plan for the long term and to take decisions to improve the adequacy of the savings they set aside for old age. However, retirement saving is a complex process influenced by numerous variables and usually initiated some time before a person actually leaves work (Huston 2010). To begin with, personal goals generate the willingness to save. Then, a person's financial behavior crystallizes in actual saving. Finally, individual factors (emotions, fears, and self-control problems) influence how an individual plan and save. This study dataset tries to offer empirical evidence regarding that retirement savings adequacy will be the result of willingness and financial behavior. Specifically, we operationalize the predictors of retirement savings adequacy (a) at the level of willingness (Financial Goals), (b) at the level of behavior (Financial Behavior) and (c) at the individual level (DA).

\subsection{Financial Goals and Financial Behavior}

Existing studies suggest that motivational factors exert an enormous influence over financial behavior and long-term savings adequacy (Hershey and Mowen 2000). In a nutshell, the specificity and breadth of goals have considerable power to orient financial behavior (Hershey et al. 2013). Meanwhile, financial goals may have different time scales and may be more or less specific in relation to retirement, varying between short-run targets (e.g., fixed monthly set-asides), medium-term plans (e.g., annual contributions to private pension funds), and long-term objectives (e.g., accumulation of a sufficient nest egg for old age).

As Eden et al. (2001) have shown, goals are the most immediate motivational determinants of behavior, because they help organize perceptions and allow people to form more specific expectations about the future and, therefore, to orient their conduct in context. People with clear goals can choose and adapt their behavior to suit needs and act accordingly in order to achieve desired objectives. As in other fields of psychological research, there is considerable empirical support for the antecedent role of 
goals in relation to both financial behavior and results. Based on the literature, this study proposes that goals will be predictors of financial behavior.

Hypothesis 1. Financial Goals at T1 predict Financial Behavior at T2.

Financial behavior consists of seeking and using financial resources in order to satisfy a given need (Huston 2010). Such behaviors can be difficult to realize, however, because resources are generally scarce compared to wants, obliging the individual how to allocate funds to satisfy often conflicting needs. Early theoretical models explaining financial behavior focused on purely rational antecedents, or on the influence of social and educational opportunities. However, ever more evidence has since accumulated to support the role of motivations and goals in responsible financial behavior (Hershey et al. 2013). Meanwhile, it has been found that people who control their financial behavior to achieve a goal are less indebted, display higher levels of saving and enjoy greater long-run financial well-being (Annink et al. 2016). This study proposes the following hypothesis:

Hypothesis 2. Financial Behavior (T2) will mediate the relationship between Financial Retirement Goals (T1) and Retirement Savings Adequacy (T3).

\subsection{Death Anxiety}

In terms of consumer behavior, thoughts of approaching death appear to increase the likelihood that people will consume more and that their appetite for luxury products will increase. Perhaps because consumption and luxury are associated with a happier life, mortality has a negative influence on saving and raises the propensity for spending and enjoyment in the short run (Mandel and Heine 1999). For example, rates of consumer spending shot up in the United States after the terrorist attacks of 11 September (Arndt et al. 2002). In general, it could be said that DA encourages active vindication of an individual's worldview, driving salient behaviors. Such defense of personal beliefs in the face of approaching mortality might take the form of outspoken support for a given political party or candidate in elections or overtly upholding religious convictions (Arrowood et al. 2017). DA has been considered as a complex construct, which includes an emotional component based on the feelings of being scared of death (Cai et al. 2017). Moreover, fear could be increased because of the economic crisis, for example, and in turn, it could affect financial decisions and behaviors. Psychological research on the topic suggested that the global economic crisis includes a raised perception of fragility (Gennaioli and Shleifer 2018), increased anger and beliefs on that specific actors should be blamed for the crisis (Waegeman et al. 2014), followed by negative emotions and psychological distress (Giorgi et al. 2015).

The research appears to show that DA is culturally conditioned (Gire 2014). Thus, numerous empirical studies reveal how manifestations of DA differ among people in western societies and their Asian peers (Kawano 2010). These differences may be emerging out of the close relationship between DA and religious orientation, life satisfaction, and beliefs about the afterlife. Though a number of empirical studies have been performed in other western societies (Nepomuceno and Laroche 2016), the influence of DA on financial behavior has not so far been explored in Spain, that has specific cultural features as a Mediterranean society.

Personal attitudes toward spending seem to be related to DA, which in turn can affect savings. For example, recent experimental studies appear to show that subjects holding strong anti-consumer attitudes tend not to increase short-run spending, even where their DA is manipulated (Nepomuceno and Laroche 2016). However, the evidence is still only indicative, and further research will be needed to examine this phenomenon among savers and the clients of financial advisors. Concerns about retirement savings adequacy have led to increasing numbers of people to avail themselves of services of this kind (Goldstein et al. 2008). These clients are obviously aware of the importance of saving and the long-run consequences of financial behavior, and in this light, the possible influence of DA on their actions clearly deserves research. 
Based on the evidence, this study proposes the following hypothesis.

Hypothesis 3. DA will act as a moderator in the relationship between Financial Goals and Retirement Savings Adequacy, mediated by Financial Behavior. In the case of high-DA subjects, this moderating effect will be expressed through an increase in the influence of Retirement Savings Adequacy on Financial Behavior.

This hypothesis thus goes a step forward in the investigation of the influence of DA on people with strong anti-consumer attitudes, who are more likely to exercise tight control over their finances (Black and Cherrier 2010). The study sample was drawn from among older clients of financial advisors, and it was therefore expected that the subjects would evince greater attention to and concern for financial matters, seeking to behave in a financially responsible manner. To sum up, the study was designed to test whether the relationship between Financial Goals at T1 and Retirement Savings Adequacy at T3 was mediated by enhanced levels of Financial Behavior at T2 and whether the effect of Financial Goals on Retirement Savings Adequacy at T3 was moderated by DA at T1.

\section{Method}

\subsection{Ethical Statement}

The Ethical Committee of the first author's University Bio-ethical Committee of the National Distance Education University (UNED) approved the Project in May 2016.

\subsection{Participants}

This study is based on data obtained from three different questionnaires answered by the same working sample (Spanish clients of financial advisory firms) at three different moments (T1, T2, and T3) with a lag of 3 months between each data collection procedure. A total sample of 340 participants ( $49 \%$ men) filled in the online questionnaire at T1. Three months later, 303 of these participants $(89 \%)$ agreed to answer the T2 questionnaire, and some 276 responded to the T3 survey (91\%) after a further three months had passed. The final sample comprised 276 questionnaires without missing data. Mean values, standard deviations, Cronbach's alphas, and correlations are reported in Table 1. Potential participants were contacted through a wider research project on financial planning for retirement proposed to financial advisory firms in Spain, two of which agreed to take part and distributed the questionnaire link to their consultants. On the first page of the survey, participants were informed about the main objective of the study, the conditions (voluntary participation, confidentiality, and freedom to leave at any time without penalty). Those who accepted could then proceed to the first set of questions.

Table 1. Mean values, standard deviations, Cronbach alphas (on the diagonal), and correlations between study variables $(\mathrm{N}=273)$.

\begin{tabular}{|c|c|c|c|c|c|c|c|c|c|}
\hline Variables & $\mathbf{M}$ & SD & 1 & 2 & 3 & 4 & 5 & 6 & 7 \\
\hline 1. Age (years) & 54.52 & 4.50 & n.a. & & & & & & \\
\hline 2. Education & n.a. & n.a. & -0.12 & n.a. & & & & & \\
\hline 3. Professional status & n.a. & n.a. & -0.11 & 0.08 & n.a. & & & & \\
\hline 4. T1 Financial Goals & 3.26 & 0.81 & $0.18^{* *}$ & 0.05 & $0.12 *$ & 0.87 & & & \\
\hline 5. T2 Financial Behavior & 2.76 & 0.84 & 0.15 * & 0.15 * & $0.18^{* *}$ & $0.19^{* *}$ & 0.90 & & \\
\hline 6. T3 Retirement Savings adequacy & 2.75 & 0.93 & -0.08 & 0.14 * & $0.16^{* *}$ & 0.31 ** & $0.45^{* *}$ & 0.83 & \\
\hline 7. T1 Death Anxiety & 2.80 & 0.79 & 0.11 & -0.04 & -0.04 & 0.07 & -0.01 & 0.02 & 0.82 \\
\hline
\end{tabular}

\subsection{Instruments}

Financial Goals (T1) were scored using the Retirement Goals Clarity scale proposed by Stawski et al. (2007), which contains five items related to the process of setting clear, well-defined retirement goals. Examples of these items include: I set specific goals for how much I will need to save for retirement; I think a 
great deal about quality for life in retirement, and I set clear goals for gaining information about retirement. Each item was answered on a 5-point Likert scale ranging from 1 (Strongly disagree) to 5 (Strongly agree).

Death Anxiety (T1) was assessed using Templer's Death Anxiety Scale (Templer 1970) as adapted for use in Spain and Mexico by Rivera-Ledesma and Montero-López (2010). This version was used instead of the earlier Spanish version produced by Tomás and Gómez (2002) because the option of a Likert-type response provided a better picture of respondents' attitudes. The scale contains 15 items related to fear of death, illness, and the end of life. Examples of the items include: I am not at all afraid to die, and It doesn't make me nervous when people talk about death. This version of the instrument showed adequate reliability indicators varying between $\alpha=0.80$ and $\alpha=0.83$ in the death anxiety scale for both samples used in the original validation study (Rivera-Ledesma and Montero-López 2010). Each item was answered on a 5-point Likert scale ranging from 1 (Strongly disagree) to 5 (Strongly agree).

Financial Behavior (T2) was measured using the Financial Behavior Scale (Danes and Haberman 2007), which contains 8 items related to the frequency of budgeting, expenditure control, and savings behaviors. Examples of items are: I track my expenses; I compare prices when I shop, and I use a budget. The five-point Likert-type response scale ranges from 1 (Almost never) to 5 (Almost always).

Retirement Savings Adequacy (T3) was measured using the Financial Experiences Index proposed by Porter and Garman (1993), which contained 15 items and was originally designed to assess individual perceptions of progress in personal and household finance. The instrument was tested using data from 466 households in Virginia, and the scale depicted predictive capacity for measures of financial wellbeing. The wording of the items was adapted in this study in order to bring it into line with retirement savings issues. Examples of items are: Compared to 5 years ago my financial assets for retirement have decreased; Compared to 5 years ago my retirement nest egg has increased; Compared to the present, my standard of living in retirement (the things that I will purchase, such as housing, food, transportation, and recreation) will remain the same; Compared to 5 years ago, the amount that I am able to save and invest for retirement has increased; and Compared to the present, my ability to meet unexpected expenses in retirement would be worse. Each item was answered on a 5-point Likert scale ranging from 1 (Strongly disagree) to 5 (Strongly agree).

In order to adapt the English questionnaires, we first translated the Retirement Goals Clarity, Financial Behavior Scale, and the Financial Experiences Index to the Spanish context. A back-translation was then carried out by a native English speaker and compared with the original questionnaire.

Education: The ISCED-97 classification from the Survey of Health, Ageing, and Retirement in Europe (Kalwij and van Soest 2005) was used, in which $1=$ Primary education or first stage of basic education, and $6=$ second stage of tertiary education. The participants were asked to report the highest school leaving certificate or university qualification they had obtained.

Reliability of the scales used in the present study, assessed by Cronbach's Alpha, is shown in the diagonal of Table 1.

\subsection{Statistical Analysis}

As suggested by Hayes (2013), indirect and moderating effects were first tested separately before going on to test the hypothesized moderated mediation model. The simple mediating effect analysis was designed to throw light on the ways in which the predictor affects the criterion variable, while the simple moderating effect analysis was intended to show when the predictor influences the criterion variable. A moderated mediation model estimating all parameters simultaneously was then tested using the PROCESS macro for SPSS (Hayes 2013).

In particular, the hypothesized relationships were assessed using Model 14 that is displayed in Figure 1. 


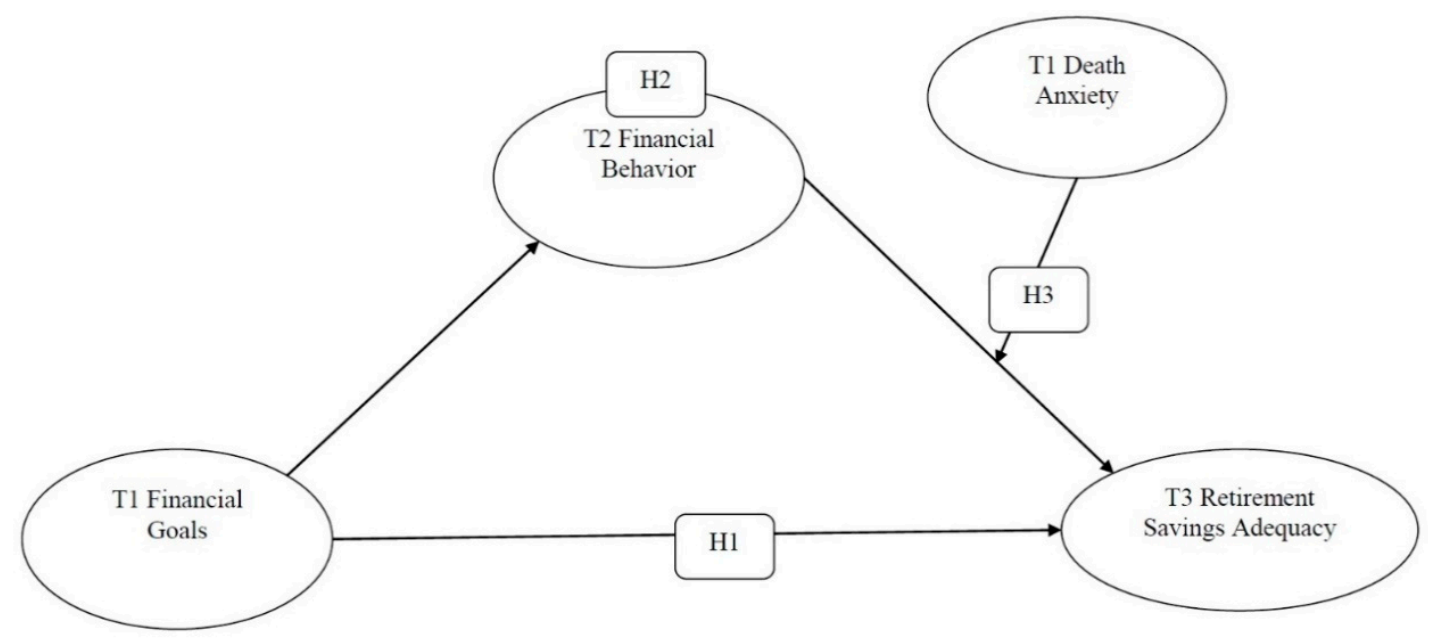

Figure 1. Theoretical model for the Study (Model 14 PROCESS).

The statistical diagram for the Model 14 analysis is shown in Figure 2.

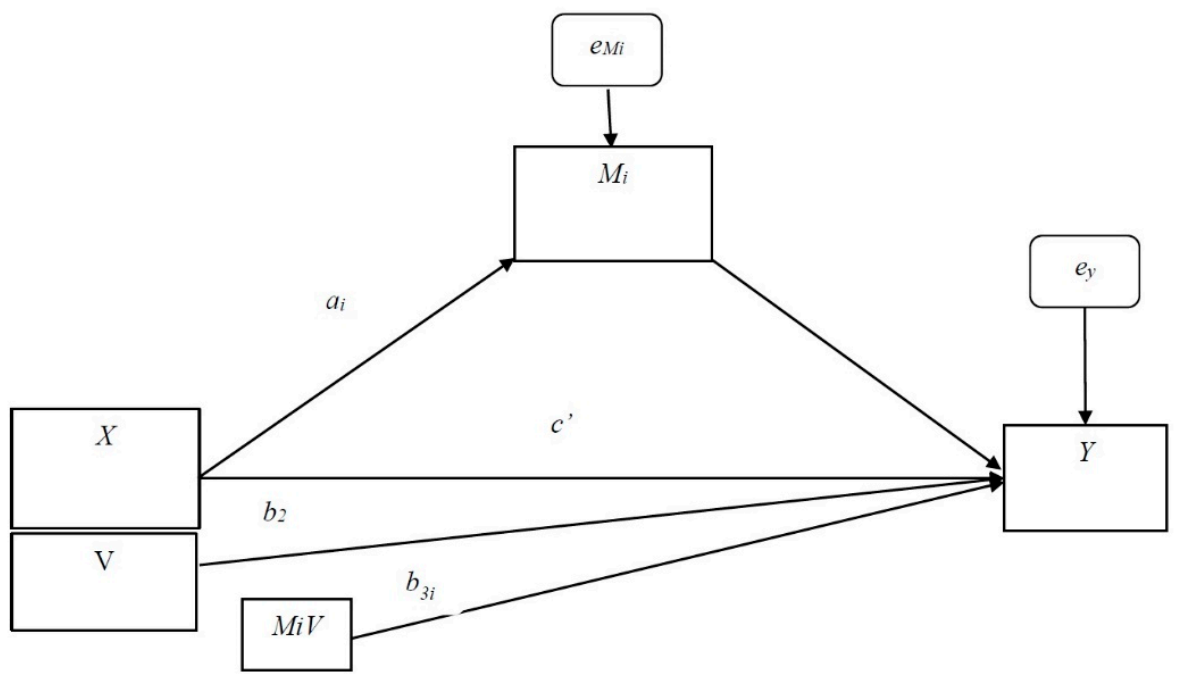

Figure 2. Statistical model for the Study (Model 14 PROCESS). Conditional indirect effect of $X$ on $Y$ through $M_{i}=a_{i}\left(b_{1 i}+b_{3 i} V\right)$.

The Model estimates the indirect effect of X (T1 Financial Goals) on Y (T3 Retirement Savings Adequacy) through M (T2 Financial Behavior), with a moderating role played by V (T1 Death Anxiety) in the $\mathrm{M} \rightarrow \mathrm{Y}$ relationship (T1 Financial Goals $\rightarrow$ T3 Retirement Savings Adequacy). The moderated mediation hypothesis is supported when the mediation process varies in line with the different values taken by the moderating variable. This procedure was based on 5000 bootstrap re-samples and provided a moderated mediation index, as well as estimates of the indirect effect and associated confidence intervals conditional on the specific levels of the moderator (Mean and +/-1 SD from Mean). When zero is not included in the $95 \%$ bias-corrected confidence interval, it may be concluded that the parameter is significantly different from zero at $p<0.05$.

\section{Results}

Before testing our model, we performed a correlation analysis of the study variables (results reported in Table 1). Age is negatively related to educational level and professional status and with Retirement Savings Adequacy. None of these relationships is statistically significant, however. Meanwhile, education and professional status exhibit positive, statistically significant relationships with Financial Behavior and Retirement Savings Adequacy. The Financial Goals variable is also 
positively and significantly related to Financial Behavior and Retirement Savings Adequacy. Financial Behavior and Retirement Savings Adequacy were also found to be positively and significantly related, while death anxiety was negatively related to education, professional status, and financial behavior but positively related to age, Financial Goals, and Retirement Savings Adequacy. However, none of these relationships was statistically significant.

In order to test our hypotheses, different regression models have been tested. The first included T1 Financial Goals as the independent variable, T3 Retirement Savings Adequacy as the dependent variable, and T2 Financial Behavior as a mediator into this relationship. The second included T2 Financial Behavior as the independent variable, T3 Retirement Savings Adequacy as the dependent variable, and the interaction term between T2 Financial Behavior and T1 Death Anxiety. Finally, the third regression model, which included T1 Financial Goals as independent variables, T3 Retirement Savings Adequacy as dependent and the moderator T1 Death Anxiety besides with the mediator T2 Financial Behavior.

\subsection{Simple Mediation Analysis}

The first analysis was designed to assess the indirect effect of T1 Financial Goals on T3 Retirement Savings Adequacy through T2 Financial Behavior. Results indicated a positive effect of T1 Financial Goals on T3 Retirement Savings Adequacy $(B=0.298, \mathrm{SE}=0.060,95 \%$ CI $[0.179 ; 0.418], p<0.001)$ and a positive association between T2 Financial Behavior and T3 Retirement Savings Adequacy $(\mathrm{B}=$ $0.476, \mathrm{SE}=0.059,95 \% \mathrm{CI}[0.359 ; 0.592], p<0.001)$. Moreover, these results supported the presence of a significant direct effect of T1 Financial Goals on T3 Retirement Savings Adequacy $(B=0.298, S E=0.060$, $95 \%$ CI $[0.179 ; 0.418], p<0.001)$ and indirect effects between these variables $(\mathrm{B}=0.07, \mathrm{SE}=0.032,95 \%$ CI [0.006; 0.143]). Subsequent Sobel tests supported this result $(z=2.18, p=0.02)$. In our study, age, education, and professional status were significantly related to T2 Financial Behavior, but there was no significant association with T3 Retirement Savings Adequacy. Taken together, these results indicate a significant mediating effect of T2 Financial Behavior on the relationship between T1 Financial Goals and T3 Retirement Savings Adequacy. Results are reported in Table 2.

Table 2. Results for the Simple mediation analysis.

\begin{tabular}{|c|c|c|c|c|c|c|c|}
\hline \multicolumn{8}{|c|}{ Outcome Variable: T3 Retirement Savings Adequacy } \\
\hline & B Coefficient & SE & $\mathbf{t}$ & $p$ & \multicolumn{2}{|c|}{ LLCI } & ULCI \\
\hline Constant & 0.0568 & 0.5486 & 3.7495 & 0.0002 & \multicolumn{2}{|c|}{0.9769} & 3.1368 \\
\hline T1 Financial Goals & 0.2986 & 0.0606 & 4.9241 & 0.0000 & \multicolumn{2}{|c|}{0.1792} & 0.4180 \\
\hline T2 Financial Behavior & 0.4758 & 0.0592 & 8.0381 & 0.0000 & \multicolumn{2}{|c|}{0.3593} & 0.5923 \\
\hline T1 Age & 0.0212 & 0.0110 & -1.9174 & 0.0562 & \multicolumn{2}{|c|}{-0.0429} & 0.0006 \\
\hline T1 Education level & 0.0375 & 0.0447 & 0.8402 & 0.4015 & \multicolumn{2}{|c|}{-0.0504} & 0.1255 \\
\hline T1 Professional category & 0.0332 & 0.0581 & 0.5708 & 0.5686 & \multicolumn{2}{|c|}{-0.0812} & 0.1475 \\
\hline \multicolumn{8}{|c|}{ Indirect effects } \\
\hline \multirow{2}{*}{\multicolumn{4}{|c|}{$\begin{array}{c}\text { T1 Financial Goals on T3 Retirement Savings Adequacy through T2 } \\
\text { Financial Behavior }\end{array}$}} & Effect & Boot SE & $\begin{array}{l}\text { Boot } \\
\text { LLCI }\end{array}$ & $\begin{array}{l}\text { Boot } \\
\text { ULCI }\end{array}$ \\
\hline & & & & 0.0666 & 0.0345 & 0.0060 & 0.1438 \\
\hline \multicolumn{8}{|c|}{ Model Summary } \\
\hline $\mathrm{R}$ & R-squared & MSE & F & df1 & \multicolumn{2}{|c|}{ df2 } & $p$ \\
\hline 0.5502 & 0.3028 & 0.6249 & 23.7964 & 5.0000 & \multicolumn{2}{|c|}{274.0000} & 0.0000 \\
\hline
\end{tabular}

Note: SE: Standard error; LLCI Lower level confidence interval, ULCI: Upper level confidence interval.

\subsection{Moderation Analysis}

The second analysis explored the moderating effect of T1 Death Anxiety on the association between T2 Financial Behavior and T3 Retirement Savings Adequacy (Results displayed in Table 3). The overall model was significant $\left(\mathrm{F}(6,273)=15.69, p<0.001, \mathrm{R}^{2}=0.256\right)$. The main effect of $\mathrm{T} 2$ Financial Behavior $(\mathrm{B}=0.126, \mathrm{SE}=0.183,95 \% \mathrm{CI}[-0.235 ; 0.488], p=0.49)$ was not significant, but 
the main effect of T1 Death Anxiety $(\mathrm{B}=-0.340, \mathrm{SE}=0.183,95 \% \mathrm{CI}[-0.701 ; 0.020], p=0.06)$ was marginally significant, and the interaction term $\left(B=0.140, S E=0.062, p=0.025, \Delta R^{2}=0.014\right)$ was fully significant. Specifically, results indicated that the association between T2 Financial Behavior on T3 Retirement Savings Adequacy increased in magnitude as the level of Death Anxiety rose from low $(-1 \mathrm{SD} ; \mathrm{B}=0.408, \mathrm{SE}=0.077, p<0.001)$ to moderate (Mean; $\mathrm{B}=0.519, \mathrm{SE}=0.060, p<0.001)$, and then to high $(+1 \mathrm{SD} ; \mathrm{B}=0.630, \mathrm{SE}=0.079, p<0.001)$.

Table 3. Results of the Moderation analysis.

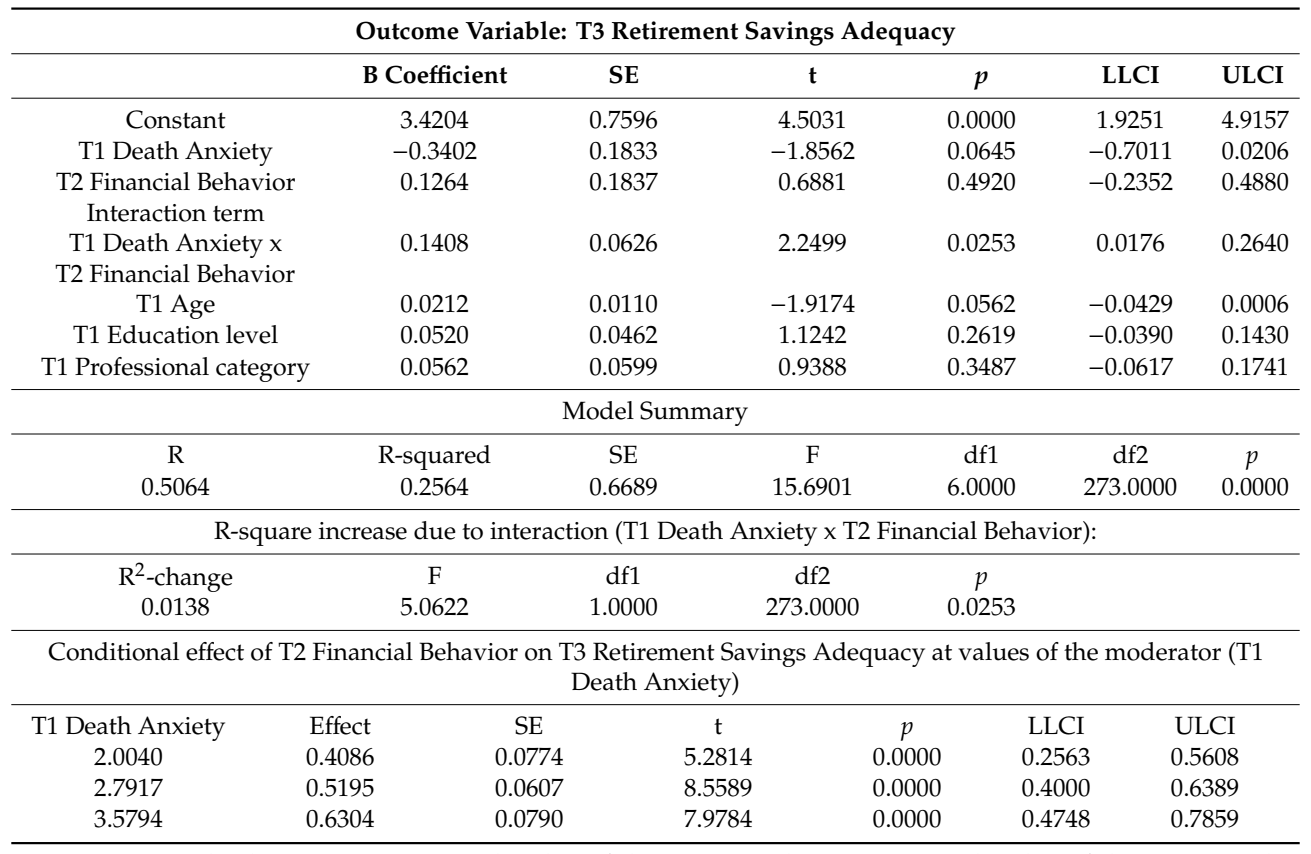

Note: SE: Standard error; LLCI Lower level confidence interval, ULCI: Upper level confidence interval.

In line with our expectations, respondents reporting greater T2 Financial Behavior perceived a higher level of T3 Retirement Savings Adequacy, where they were distinguished by a strong T1 Death Anxiety (See Figure 3).

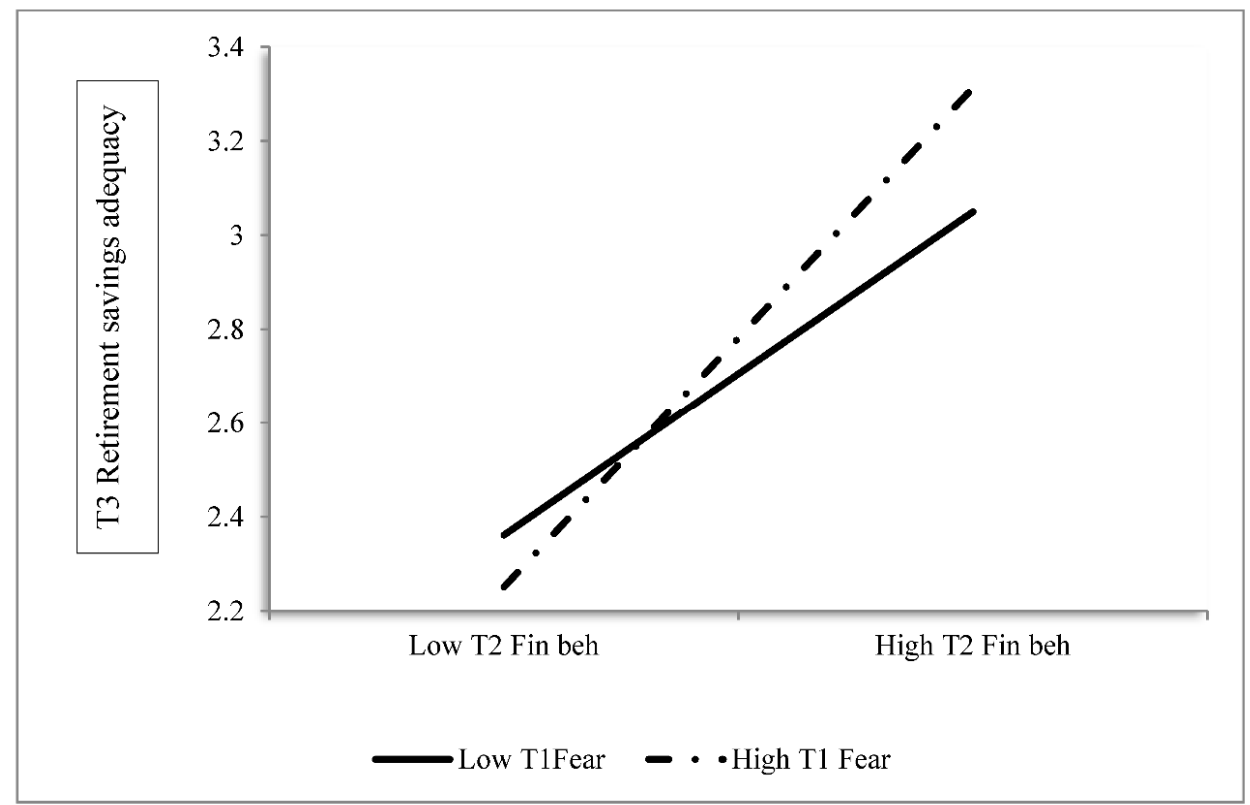

Figure 3. Interaction of T2 Financial Behavior and T1 DA in predicting T3 Retirement Savings Adequacy. 


\subsection{Moderated Mediation}

The moderated mediation index was significant: $\mathrm{B}=0.020, \mathrm{SE}=0.012,95 \% \mathrm{CI}[0.001 ; 0.053]$. Furthermore, the analysis revealed a conditional indirect effect of T1 Financial Goals on T3 Retirement Savings Adequacy through T2 Financial Behavior. This indirect effect was significant at low $(-1 \mathrm{SD} ; \mathrm{B}=$ $0.051, \mathrm{SE}=0.030,95 \% \mathrm{CI}[0.004 ; 0.121])$, moderate (Mean; $\mathrm{B}=0.067, \mathrm{SE}=0.034,95 \% \mathrm{CI}[0.005 ; 0.138])$, and high levels of T1 Death Anxiety (+1SD; B $=0.083$, SE $=0.040,95 \%$ CI $[0.008 ; 0.166])$, implying that the perceived level of T2 Financial Behavior mediates the relationship between T1 Financial Goals and T3 Retirement Savings Adequacy for respondents distinguished by low to high levels of T1 Death Anxiety. Results are displayed in Table 4.

Table 4. Conditional indirect effects of T1 Financial Goals on T3 Retirement Savings Adequacy through T2 Financial Behavior as a function of the T1 Death Anxiety levels.

\begin{tabular}{ccccc}
\hline T1 Death Anxiety & Effect & Boot SE & Boot LLCI & Boot ULCI \\
\hline 2.0040 & 0.0514 & 0.0300 & 0.0045 & 0.1210 \\
2.7917 & 0.0671 & 0.0342 & 0.0049 & 0.1382 \\
3.5794 & 0.0829 & 0.0404 & 0.0076 & 0.1663 \\
\hline
\end{tabular}

\section{Discussion}

This study was designed to throw light on the moderating role of DA in relation to financial goals and retirement savings adequacy as mediated by financial behavior among a sample of 40-plus clients of Spanish financial advisory firms, as reflected in our key findings. In the first place, the study supports the hypothesis that DA can affect Retirement Savings Adequacy. This finding, in turn, confirms one of the key postulates of recent research, which is that affective influences have important effects on people's financial success (Gutierrez and Hershey 2013; Yu and Chen 2016). Specifically, the moderating role of DA in the relationship between Financial Behavior and Retirement Savings Adequacy ties in with research into the adoption of different consumption styles by different individuals. Thus, the clients of financial advisory firms could be said to act as "frugality consumers," who initially restrict their spending in order to achieve long-term goals (Black and Cherrier 2010). As lifestyle options gradually solidify into patterns of day-to-day behavior, however, these options become an identity or defining the characteristic of such people, creating positive bedrock of self-esteem against the materialistic behavior so common in society at large.

Meanwhile, the findings from the present study suggest that further work could be done in this field. Specifically, our results concur with goal/behavior/saving models (Hershey et al. 2013), supporting the idea that positive financial outcomes should be conceived as embodying rather more than mere rational decision-making, but also the interplay of uncontrolled feelings and thoughts arising from cognitive assessments of the saver's personal time horizon and approaching mortality (Major et al. 2016; Nepomuceno and Laroche 2016). Secondly, the impact of clarity and the specificity of Financial Goals on retirement saving is explained by Financial Behavior. This finding is in accord with a long line of research into the influence of goals on the materialization of financial behavior (Hershey and Mowen 2000; Hershey et al. 2007). However, it cannot account for the adequacy of savings, which can only be explained if the role played by death anxiety in these relationships is also considered, since the perception of clear goals is intensified by approaching mortality and the apprehensions it awakens.

The three-wave's design of this study is intended to enrich debate about the behavioral and emotional processes which foster saving and investment for retirement. Nevertheless, we should also note some limitations. In the first place, the use of self-reporting questionnaires is associated with common variance method bias and the risk of subjectivity. However, the study was designed to explore the role of perceptions of Financial Goals, Financial Behavior, Retirement Savings Adequacy and DA among the 40-plus clients of financial advisory firms, and the use of perceptive measures seemed the best way to throw light on these constructs. Meanwhile, the relatively small size of the sample could 
diminish the statistical power of the analysis, affecting the assessment of relationships between the variables. In the same vein, we should recognize that the main reason for a three months lag in the data collection was in order to avoid higher abandon rates between the participants. Hence, future studies could base the designs in stronger theoretical supports.

Finally, this study looks at a sample of clients of financial advisory firms. This decision provides a novel approach and adds value to the study, but we must also recognize that the target group is made up of people who may be assumed to be particularly aware of the importance of money matters, which may make it difficult to generalize findings to a broader population. Due to the fact that inclusion only of clients of financial advisory services entails a potential endogeneity bias, another further research avenue could include a non-financial advisory client group, in order to better tease the role of the financial counselor on clients' decisions, as well as others influences from the social context (Leder et al. 2016).

In the second place, this paper should be treated as an initial attempt to investigate the role of emotions in relation to financial goals and outcomes measured in terms of behaviors. Our exploration focuses on the negative aspects of the feelings stirred by the approach of death, but it does not address the possibility of positive emotional responses (Major et al. 2016). While saving entails delayed gratification and may, therefore, be disagreeable in the short run, our research into consumer lifestyles nonetheless suggests that frugality consumers may actually take a certain pleasure in saving. In this light, future studies should look into the influence of both aspects of emotions in the materialization of financial behaviors and their outcomes.

This paper points to a promising avenue for future research and, indeed, for financial counseling. Various published papers advocate customizing financial services proposals in line with the needs of individual clients. In this context, the present study stresses that "quantity" does not necessarily equate with "quality", but that the products and services offered by financial advisory firms should take into consideration the stage of life reached by individual clients and their specific time horizons (Coskun et al. 2018).

Meanwhile, this research centers on the emotional influences which might foster and increase saving, but this does not mean we should ignore the body of research addressing the factors which may hinder or reduce it, such as the tendency to procrastinate (Rahimi et al. 2016; Xu et al. 2016) and risk aversion (Byrne and Worthy 2016). One of the avenues for future research should include the control of clients' risk tolerance and time preferences, which are widely assessed in empirical studies (Canepa and Khaled 2018; Lindset and Mork 2019) as well as in professional settings. Personal advisors and other professionals involved in marketing financial products and services would benefit not only from a knowledge of the specific characteristics of their clients but also from a more detailed analysis of how potentially positive and negative influences may interact, such as emotional intelligence (Asad et al. 2018), earlier financial socialization experiences, and couple's saving intentions, among others. In the same vein, the role of culture in shaping the cognitive mechanisms that affect emotion perceptions should be taken into account, as has been recently stated (Engelmann and Pogosyan 2013). Specifically, given that both death and grief have a strong cultural meaning, which could vary as a function of time, situation and beliefs, it is necessary to know how these influences could affect people in their planning for aging and retirement (Bermejo et al. 2016). In the same way, other relevant variables could be considered as a control variable in future studies, for instance, the size and composition of the household, the number of children, amount of the future pension, current savings and financial literacy, that would affect the results in a significant manner.

Finally, it will be important to persist with the task of financial education begun in recent years, seeking to provide young adults, adolescents, and even children with a basic knowledge of how money works (Harkin 2017). In this context, it will be important not only to help people understand that long-term financial planning matters, but also to ensure they are aware of the relative salience of different financial concerns at different stages over the course of their lives (Zeng et al. 2019) so that 
they are able to take early action to guarantee the availability of resources at times of personal frailty (Claudelin et al. 2018).

Author Contributions: Conceptualization, P.G., M.H., T.H. and G.T.; Data curation, P.G., M.H., T.H. and G.T.; Investigation, P.G., and G.T.; Methodology, P.G., and G.T.; Writing-original draft, P.G., and G.T.; Writing-review \& editing, P.G., M.H., T.H. and G.T.

Funding: This research received no external funding.

Conflicts of Interest: The authors declare no conflict of interest.

\section{References}

Annink, Anne, Marjan Gorgievski, and Laura DulkAnnink. 2016. Financial hardship and well-being: A cross-national comparison among the European self-employed. European Journal of Work and Organizational Psychology 25: 645-57. [CrossRef]

Arndt, Jamie, Jeff Greenberg, Jeff Schimel, Tom Pyszczynski, and Sheldon Solomon. 2002. To belong or not to belong, that is the question: Terror management and identification with gender and ethnicity. Journal of Personality and Social Psychology 83: 26. [CrossRef] [PubMed]

Arrowood, Robert, Cathy Cox, and Naomi Ekas. 2017. Mortality salience increases death-thought accessibility and worldview defense among high Broad Autism Phenotype (BAP) individuals. Personality and Individual Differences 113: 88-95. [CrossRef]

Asad, Ali Shah Syed, Tian Yezhuang, Adnan Muhammad Shah, Dilawar Khan Durrani, and Syed Jamal Shah. 2018. Fear of terror and psychological well-being: The moderating role of emotional intelligence. International Journal of Environmental Research and Public Health 15: 2554. [CrossRef] [PubMed]

Bermejo, José Carlos, Marta Villacieros, and Invencion Fernandez-Quijano. 2016. Escala de mitos en duelo. relación con el estilo de afrontamiento evitativo y validación psicométrica [Scale of myths in duel relationship with avoidant coping style and psychometric validation]. Acción Psicológica 13: 129-42. [CrossRef]

Black, Iain, and Helene Cherrier. 2010. Anti-consumption as part of living a sustainable lifestyle: Daily practices, contextual motivations and subjective values. Journal of Consumer Behaviour 9: 437-53. [CrossRef]

Budowski, Monica, Sebastian Schief, and Rebekka Sieber. 2016. Precariousness and Quality of Life-A Qualitative Perspective on Quality of Life of Households in Precarious Prosperity in Switzerland and Spain. Applied Research in Quality of Life 11: 1035-58. [CrossRef]

Byrne, Kaileigh A., and Darrell Worthy. 2016. Toward a mechanistic account of gender differences in reward-based decision-making. Journal of Neuroscience, Psychology, and Economics 9: 157-68. [CrossRef]

Cai, Wei, Yung-Lung Tang, Sung Wu, and Hong Li. 2017. Scale of Death Anxiety (SDA): Development and Validation. Frontiers in Psychology 8: 858. [CrossRef]

Canepa, Alessandra, and Fawaz Khaled. 2018. Housing, Housing Finance, and Credit Risk. International Journal of Financial Studies 6: 50. [CrossRef]

Claudelin, Anna, Sini Järvelä, Ville Uusitalo, Maija Leino, and Lassi Linnanen. 2018. The Economic Potential to Support Sustainability through Household Consumption Choices. Sustainability 10: 3961. [CrossRef]

Coskun, Yener, Burak Atasoy, Giacomo Morri, and Esra Alp. 2018. Wealth Effects on Household Final Consumption: Stock and Housing Market Channels. International Journal of Financial Studies 6: 57. [CrossRef]

Danes, Sharon, and Heather Haberman. 2007. Teen financial knowledge, self-efficacy, and behavior: A gendered view. Financial Counseling and Planning Education 18: 48-60.

Dong, Fangyuan, Nick Halen, Kristen Moore, and Quinglai Zeng. 2019. Efficient retirement portfolios: using life insurance to meet income and bequest goals in retirement. Risks 7: 9. [CrossRef]

Eden, Daniel, Miriam Erez, Uwe Kleinbeck, and Henk Thierry. 2001. Work Motivation in the Context of a Globalizing Economy. Mahwah: Lawrence Erlbaum Associates.

Engelmann, Jan, and Marianna Pogosyan. 2013. Emotion perception across cultures: The role of cognitive mechanisms. Frontiers in Psychology 4: 118. [CrossRef] [PubMed]

Gennaioli, Nicola, and Andrei Shleifer. 2018. A Crisis of Beliefs: Investor Psychology and Financial Fragility. Princeton: Princeton University Press.

Gire, James. 2014. How death imitates life: Cultural influences on conceptions of death and dying. Online Reading in Psychology and Culture 6: 3-25. [CrossRef] 
Giorgi, Gabriele, Mindy Shoss, and José María Leon-Perez. 2015. Going beyond workplace stressors: Economic crisis and perceived employability in relation to psychological distress and job dissatisfaction. International Journal of Stress Management 22: 137. [CrossRef]

Goldstein, Daniel, Eric Johnson, and William Sharpe. 2008. Choosing outcomes versus choosing products: Consumer-focused retirement investment advice. Journal of Consumer Research 35: 440-56. [CrossRef]

Gutierrez, Helen. C., and Douglas Hershey. 2013. Impact of retirement worry on information processing. Journal of Neuroscience, Psychology, and Economics 6: 264. [CrossRef]

Han, Duke, Patricia A. Boyle, Brian D. James, Lei Yu, and David Bennett. 2015. Poorer financial and health literacy among community-dwelling older adults with mild cognitive impairment. Journal of Aging and Health 27: 1105-17. [CrossRef]

Harkin, Ben. 2017. Improving Financial Management via Contemplation: Novel Interventions and Findings in Laboratory and Applied Settings. Frontiers in Psychology 8: 327. [CrossRef] [PubMed]

Hayes, Andrew F. 2013. Introduction to Mediation, Moderation, and Conditional Process Analysis: A Regression-Based Approach. New York: Guilford Press.

Hershey, Douglas A., and John. C. Mowen. 2000. Psychological determinants of financial preparedness for retirement. The Gerontologist 40: 687-97. [CrossRef] [PubMed]

Hershey, Douglas A., Joy M. Jacobs-Lawson, and James T. Austin. 2013. Effective Financial Planning for Retirement. In The Oxford Handbook of Retirement. Edited by Mo Wang. Oxford: Oxford University Press, pp. 402-30.

Hershey, Douglas A., Joy M. Jacobs-Lawson, John McArdle, and Fumiaki Hamagami. 2007. Psychological foundations of financial planning for retirement. Journal of Adult Development 14: 26-36. [CrossRef]

Huston, Sandra J. 2010. Measuring financial literacy. Journal of Consumer Affairs 44: 296-316. [CrossRef]

Kalwij, Adriaan, and Arthut van Soest. 2005. Item Non-Response and Alternative Imputation Procedures. In The Survey of Health, Aging, and Retirement in Europe-Methodology. Edited by Axel Börsch-Supan and Hendrik Jürges. Mannheim: Mannheim Research Institute for the Economics of Aging (MEA), pp. 128-50.

Kawano, Satsuki. 2010. A sociocultural analysis of death anxiety among older Japanese urbanites in a citizens' movement. OMEGA—Journal of Death and Dying 62: 369-86. [CrossRef]

Leder, Johannes, Leonhard Schilbach, and Aandreas Mojzisch. 2016. Strategic decision-making and social skills: Integrating behavioral economics and social cognition research. International Journal of Financial Studies 4: 22. [CrossRef]

Lindset, Snorre, and Knut A. Mork. 2019. Risk Taking and Fiscal Smoothing with Sovereign Wealth Funds in Advanced Economies. International Journal of Financial Studies 7: 4. [CrossRef]

Major, Rochelle J., William J. Whelton, Jeff Schimel, and Donald Sharpe. 2016. Older Adults and the Fear of Death: The Protective Function of Generativity. Canadian Journal on Aging/La Revue Canadienne du Vieillissement 35: 261-72.

Mandel, Naomi, and Steven. J. Heine. 1999. Terror management and marketing: He who dies with the most toys wins. Advances in Consumer Research 26: 527-32.

Nepomuceno, Marcelo Vinhal, and Michel Laroche. 2016. Do I Fear Death? The Effects of Mortality Salience on Anti-Consumption Lifestyles. Journal of Consumer Affairs 50: 124-44. [CrossRef]

Osborne, Jason W. 2016. An Existential Perspective on Death Anxiety, Retirement, and Related Research Problems. Canadian Journal on Aging/La Revue Canadienne du Vieillissement 36: 246-55. [CrossRef] [PubMed]

Park, Sojung, Eunsun Kwon, and Hyunjoo Lee. 2017. Life Course Trajectories of Later-Life Cognitive Functions: Does Social Engagement in Old Age Matter? International Journal of Environmental Research and Public Health 14: 393. [CrossRef] [PubMed]

Porter, Nancy M., and Thomas Garman. 1993. Testing a conceptual model of financial well-being. Financial Counseling and Planning 4: 135-64.

Rahimi, Sonia, Nathan C. Hall, and Timothy A. Pychyl. 2016. Attributions of Responsibility and Blame for Procrastination Behavior. Frontiers in Psychology 7: 1179. [CrossRef] [PubMed]

Rivera-Ledesma, Armando, and María Montero-López. 2010. Propiedades psicométricas de la Escala de ansiedad ante la Muerte de Templer en sujetos Mexicanos. [Templer's death anxiety scale: Mexican psychometric properties]. Diversitas 6: 135-40. [CrossRef]

Stawski, Robert S., Douglas A. Hershey, and Joy M. Jacobs-Lawson. 2007. Goal clarity and financial planning activities as determinants of retirement savings contributions. The International Journal of Aging and Human Development 64: 13-32. [CrossRef] [PubMed] 
Templer, Donald. 1970. The construction and validation of a Death Anxiety Scale. Journal of General Psychology 82: 165-77. [CrossRef]

Tomás, Joaquín, and Juana Gómez. 2002. Psychometric properties of the Spanish form of Templer's death anxiety scale. Psychological Reports 91: 1116-20. [CrossRef]

Topa, Gabriela, and Teresa Herrador-Alcaide. 2016. Procrastination and financial planning for retirement: A moderated mediation analysis. Journal of Neuroscience, Psychology, and Economics 9: 169-81. [CrossRef]

Waegeman, Anja, Carolyn H. Declerck, Christophe Boone, Wim Van Hecke, and Paul M. Parizel. 2014. Individual differences in self-control in a time discounting task: An fMRI study. Journal of Neuroscience, Psychology, and Economics 7: 65-79. [CrossRef]

Xu, Ping, Claudia González-Vallejo, and Zhe H. Xiong. 2016. State anxiety reduces procrastinating behavior. Motivation and Emotion 40: 625-37. [CrossRef]

$\mathrm{Yu}$, Zonghuo, and Li Chen. 2016. Income and Well-Being: Relative Income and Absolute Income Weaken Negative Emotion, but only Relative Income Improves Positive Emotion. Frontiers in Psychology 7: 2012. [CrossRef] [PubMed]

Zeng, Shihong, Xinwei Zhang, Xiaowei Wang, and Guowang Zeng. 2019. Population Aging, Household Savings and Asset Prices: A Study Based on Urban Commercial Housing Prices. Sustainability 11: 3194. [CrossRef]

(C) 2019 by the authors. Licensee MDPI, Basel, Switzerland. This article is an open access article distributed under the terms and conditions of the Creative Commons Attribution (CC BY) license (http://creativecommons.org/licenses/by/4.0/). 